\title{
IGLESIAS Y ALTARES DEL HOSPITAL DE LA PURÍSIMA CONCEPCIÓN DE TUNJA $(1553-1835)$
}

\section{CHURCHES AND ALTARPIECES AT THE HOSPITAL DE LA PURÍSIMA CONCEPCIÓN IN TUNJA (1553-1835)}

\author{
Abel Fernando Martínez Martín \\ Universidad Pedagógica y Tecnológica de Colombia. Colombia \\ ORCID: 0000-0002-4621-6072 \\ abelfmartinez@gmail.com \\ Andrés Ricardo Otálora Cascante \\ Universidad Nacional de Colombia. Colombia \\ ORCID: 0000-0002-0793-4602 \\ arotalorac@unal.edu.co
}

\begin{abstract}
Este artículo analiza con fuentes de archivo los cambios ocurridos en las tres sedes del hospital de la Purísima Concepción de la ciudad de Tunja en el Nuevo Reino de Granada, administrado por la orden de San Juan de Dios entre los siglos XVII y XIX. La primera sede del convento-hospital, el traslado al colegio de los jesuitas tras la expulsión de la Compañía y su último destino en el convento de los agustinos calzados, por orden de la República de Colombia en el siglo XIX. Se rastrean estatuas, cuadros y retablos desaparecidos tras la extinción de la Orden Hospitalaria, que han aparecido en Bogotá y en otras iglesias de Tunja, en especial la pequeña recoleta de El Topo.

Palabras clave: Tunja; Colombia; hospital de la Purísima Concepción; Orden Hospitalaria de San Juan de Dios; arte neogranadino.
\end{abstract}

This paper uses file feeds to account for changes occured in the various sites of Hospital de la Purísima Concepción in Tunja during the historical period in Colombia known as New Kingdom of Granada. The said hospital was ran by the Hospitaller Order of the Brothers of Saint John of God during the $17^{\text {th }}$ and the $19^{\text {th }}$ centuries. The paper analyses the changes brought about by the hospital various relocation from its original site to the Jesuit College and from there to the Discalded Augustinians Convent. The latter relocation was sanctioned by the national Government of Colombia in the $19^{\text {th }}$ century. Throughout the following lines, missing statues, pictures and altarpieces are traced to various churches located in Bogotá and Tunja, especially the small Church of El Topo.

Keywords: Tunja; Colombia; Hospital de la Purísima Concepción; Hospitaller Order of the Brothers of Saint John of God; New Granada art. 


\section{INTRODUCCIÓN}

En 1541, dos años después de realizarse la fundación de la ciudad de Tunja en el altiplano andino del Nuevo Reino de Granada, el emperador Carlos V ordenó que se fundaran hospitales en todos los poblados destinados a atender a los pobres de solemnidad. El hospital de Tunja, uno de los primeros del Nuevo Reino de Granada, existía ya en el año 1553 administrado por la cofradía de Nuestra Señora de la Concepción. En 1546, siete años después de la fundación de la ciudad de Tunja, ubicada en los Andes Orientales a 2.800 metros sobre el nivel del mar, el hospital se está edificando como mandaban las instrucciones de fundar, a las afueras, en la tercera calle real, salida hacia Vélez, camino peregrino de Santiago y lugar de entrada de la acequia que llevaba el agua hasta la plaza mayor.

No existen en Tunja hospitales para indios y para españoles; por siglos solo existirá un hospital general. Del siglo XVI al XIX el hospital de la Purísima Concepción de Tunja seguirá sirviendo para el ejercicio de la virtud teologal de la caridad y de las obras de misericordia por parte de los vecinos. En la ciudad se asentaron los conquistadores y sus familias convertidos en encomenderos, rodeados de 160 pueblos repartidos en 77 encomiendas ${ }^{1}$. En la Descripción de Tunja de 1610 se ratifica la advocación del hospital a Nuestra Señora de la Concepción; se señala que contaba con un cirujano y un barbero y atendía a indios y españoles, que escaseaban las camas y que vivía en la pobreza; poseía además de las dos enfermerías, un cementerio anexo y una pequeña iglesia ${ }^{2}$. Tras la división de la ciudad en tres parroquias, el hospital queda ubicado en jurisdicción de Santa Bárbara. A este pequeño local ${ }^{3}$ llegarán para administrarlo los hermanos hospitalarios de Juan de Dios en los años treinta del siglo XVII.

${ }^{1}$ COLMENARES, Germán: La provincia de Tunja en el Nuevo Reino de Granada. Tunja, 1984, p. 10.

2 TORRES DE MENDOZA, Luis: Colección de documentos ineditos relativos al descubrimiento, conquista y organización de las antiguas posesiones españolas de America y Oceanía, sacados de los Archivos del Reino, y muy especialmente del de Indias. T. IX. Madrid, 1868, p. 447.

${ }^{3}$ En el artículo sobre el retablo para la cofradía de la Soledad de Tunja, de los historiadores Herrera y Vargas aparecido en el número 29 de Laboratorio de Arte de 2017, se menciona el Humilladero que ubican en la tercera calle real al lado del hospital de la Limpia Concepción, que se cita como de San Juan de Dios, nombre que no tuvo el hospital colonial en Tunja. La localización se desprende de dos referencias de Porras Collantes. PORRAS, Ernesto: Crónica colonial de Tunja y su provincia. Tunja, 2006, pp. 143 y 266. Este autor, si bien utiliza fuentes de archivo, en un mismo párrafo sobre un mismo tema, usa actas capitulares de varios siglos que correlaciona con el mapa de Tunja de 1623 realizado para la división de la ciudad en tres parroquias. La cofradía de la Soledad tenía como fundador y mayordomo al encomendero Pedro Pacheco, protagonista del "Motín de las Alcabalas", del que se sabe que fue hijo de María de Carvajal y Diego García Pacheco, quien llegó con el gobernador Jerónimo Lebrón. HERRERA, Francisco y VARGAS, Liliana: 
La actividad misional de los hermanos de Juan de Dios al servicio de la monarquía está estrechamente relacionada con la vida del fundador, de la primero fraternidad y luego orden, Juan Ciudad y Duarte (1495-1550) ${ }^{4}$. Los hospitalarios no son al inicio una orden religiosa, sino una congregación de hermanos que voluntariamente ingresan a una comunidad que adoptó una regla de convivencia monástica -la de San Agustín-, cuya preocupación se centraba en el ejercicio de la misericordia con los pobres enfermos y no en desarrollos teológicos ${ }^{5}$.

Por real cédula de 2 de diciembre de 1595, Felipe II le da licencia a la congregación de Juan de Dios para fundar hospitales en América y autorizaba a pasar a Indias a fray Francisco Hernández y otros cinco hospitalarios, para hacerse cargo de los hospitales de Cartagena de Indias, Nombre de Dios y Panamá6.

En 1635 el prior del convento-hospital de San Sebastián de Cartagena de Indias, fray Diego de Medina ${ }^{7}$, es enviado por el comisario general hospitalario a Santafé, capital del Nuevo Reino, para ayudar en la fundación del convento

\footnotetext{
"En los orígenes de la retablística neogranadina: trazas y contrato para un retablo de Tunja (1586)", Laboratorio de Arte, 29, 2017, pp. 216, 219; y AVELLANEDA, José Ignacio: La jornada de Jerónimo Lebrón al Nuevo Reino de Granada. Bogotá, 1993, p. 81. Pedro Pacheco de Carvajal, heredero del mayorazgo, fue regidor de Tunja y encomendero de Garagoa y Tinjacá, se casó con Isabel de Carvajal y fueron padres de Diego Pacheco Carvajal, quien en 1632 era encomendero de Socha. FLÓREZ DE OCARIZ, Juan: Libro segundo de las genealogías del Nuevo Reino de Granada. Bogotá, 1990 (edición facsimilar de la impresión de Madrid de 1676), p. 199. En el plano de 1623 se dibuja una aislada propiedad a nombre de la viuda del encomendero Pedro Pacheco, al occidente, por el mismo camino a Vélez, cerca del hospital de la Concepción, lugar que no era su casa de habitación. CORTÉS, Vicenta: “Tunja y sus vecinos", Repertorio Boyacense, 317, 1985, pp. 53-54.

${ }^{4}$ Joao Ciudad Duarte nace en Montemayor el Nuevo, en la provincia de Alentejo, perteneciente al obispado de Évora, capital de Portugal en ese tiempo, en 1495. En España, la literatura hagiográfica y la oratoria panegírica han aplicado el título de pater pauperum (padre de los pobres) por antonomasia a los santos Juan de Dios y Tomás de Villanueva. DE GOVEA, Antonio: Historia de la vida, muerte, y milagros del glorioso patriarca y Padre de los Pobres S. Juan de Dios, fundador de la orden de la Hospitalidad. Lisboa, 1658. Fue beatificado en 1630 y canonizado en 1690. La producción artística sobre San Juan de Dios aumentó tras su beatificación. CARRASCO, Daniel: "San Juan de Dios: un tipo iconográfico peculiar. En torno a la evolución pictórica de la imagen devota", Archivo Hospitalario, 2, 2004, pp. 195-201.

${ }_{5}$ ALBERRO, Solange: Apuntes para la historia de la Orden hospitalaria de San Juan de Dios en la Nueva España-México 1604-2004. México, 2005, p. 211.

${ }^{6}$ ROCHER, Adriana: "La orden hospitalaria de San Juan de Dios en Filipinas siglos XVII y XVIII", Hispania Sacra, 138, 2016, pp. 619-630.

7 DE LA TOR RE, Francisco: Diccionario de hermanos de la congregación española. T. J-K-L-M. Granada, 2012, pp. 1437-1441.
} 
y hospital de San Pedro ${ }^{8}$. Este hospitalario pasa luego a la cercana ciudad de Tunja en $1636^{\circ}$, para fundar el convento de la orden de Juan de Dios y encargarse “a perpetuidad" del hospital de la Purísima Concepción, local que alojaba anualmente a 150 pobres enfermos en dos enfermerías y 22 camas: 12 camas para hombres y 10 para mujeres, y una pequeña iglesia sobre la tercera calle real.

Un documento de 1642 sobre la visita del cabildo al hospital administrado por la orden de Juan de Dios es la primera descripción de los bienes muebles de la iglesia del convento-hospital de la Purísima Concepción. Como todos los inventarios posteriores, describe los altares, ornamentos, alhajas, reliquias, imágenes de bulto y cuadros presentes en la iglesia, sacristía y enfermerías. Los hospitalarios renovaron las dos enfermerías y atendían a 220 pobres enfermos al año. Terminan la sacristía y la iglesia del hospital, que cuenta con un cuadro de la Limpia Concepción, patrona del establecimiento, perteneciente a la antigua cofradía, un sagrario dorado y dos altares laterales nuevos, uno del Espíritu Santo y otro de la "la Madre de Dios de Chiquinquirá" 10 , así como una imagen de bulto del beato Juan de Dios "bien acabada". En la iglesia se celebraban tres misas cantadas en la semana ${ }^{11}$.

A partir de la descripción de la primitiva iglesia del convento-hospital de la Purísima Concepción de Tunja de 1642, se inicia la historia del trasegar de los bienes muebles de uso religioso por las sedes hospitalarias que los hermanos de San Juan de Dios ocuparían en los siglos siguientes, en su peregrinar por varios

${ }^{8}$ El acta de posesión de las casas del hospital de San Pedro es del 20 de julio de 1635. Sociedad Colombiana de Historia de la Medicina: Acta de Fundación del Hospital San Juan de Dios. Bogotá, 1985.

${ }^{9}$ Benjamín Agudelo sostiene que los hermanos de San Juan de Dios no llegaron a Tunja en 1636 sino en 1639, aunque este último año corresponde a la fecha de la muerte del prior hospitalario de Santafé y Tunja, Diego de Medina. AGUDELO, Benjamín: Los hijos de San Juan de Dios en Nueva Granada, Colombia. T. V. Bogotá, 1983, p. 841.

${ }^{10}$ Esta advocación propia del Nuevo Reino de Granada se refiere a una popular pintura sobre una manta de algodón hecha por Alonso de Narváez a petición del encomendero Antonio de Santana entre 1555 y 1556 en su taller a una cuadra del hospital, destinada a la iglesia del pueblo de indios de Suta. Ante el deterioro del cuadro, el cura doctrinero lo mandó quitar en 1578. Catalina García de Irlos, viuda del encomendero Santana, lo llevó a sus aposentos en Chiquinquirá donde suceden los "milagros" de la "Renovación" en 1586 y 1589. La Virgen de Chiquinquirá fue traída a Tunja por varios días, a causa de las epidemias de 1587 y 1633 que diezmaron la población indígena. Desde entonces se le atribuyen a la imagen propiedades taumatúrgicas. El cabildo y los encomenderos tunjanos patrocinaron la construcción de la iglesia en Chiquinquirá y en 1645 levantaron en su honor una ermita en la entrada a Tunja por la loma de los Ahorcados, camino que entra a la ciudad por la tercera calle real, donde se ubica el convento hospital.

11 AGI (Archivo Genera de Indias), Indiferente General, leg. 3076. Citado por AGUDELO, Benjamín: Los hijos..., op. cit., pp. 840-844. 
conventos e iglesias de la ciudad. Este recorrido es el objetivo principal del presente artículo (Figura 1). En la actualidad, la mayoría de estas obras han desaparecido o se encuentran expuestas descontextualizadas en iglesias de Tunja y Bogotá. A través de los inventarios que se hacen en las visitas de la Orden Hospitalaria de San Juan de Dios, fue posible reconstruir su presencia en la ciudad, no solo su labor al servicio de los pobres enfermos en nombre de la caridad, sino el rico patrimonio artístico de la ciudad colonial.

De esta primera iglesia y su hospital, edificaciones desaparecidas a fines del siglo XIX, no han quedado otros vestigios que su portada manierista en piedra que tiene en el remate un nicho con la imagen de la Pura y Limpia Concepción, también de piedra, cuya puerta con buena clavazón dorada, cerrojo, chapa y llave fue trasplantada a la iglesia del convento agustino descalzo de El Topo, levantado a extramuros en 1729. Portada que fue hasta hace poco la única referencia de la presencia de los hospitalarios en la ciudad. Según los historiadores Rubio y Briceño, se trasladó a El Topo entre finales del siglo XIX y principios del XX ${ }^{12}$ (Figura 2).

En cuanto a la estatua del patrón de la orden, acompañó en sus traslados a los hospitalarios y aparece en la iglesia de los expulsados jesuitas a finales del siglo XVIII y en la de los agustinos calzados en el XIX hasta la expulsión de los hospitalarios por la República en 1835. Su paso por la ciudad terminó en 1940, cuando las hermanas dominicas de La Presentación administraban el hospital de Caridad en su cuarta sede, ubicada en el convento de Santa Clara la Real. Allí, las hermanas la entregaron al hospitalario José María Atmeller, quien la trasladó a Bogotá. En 1982 fue enviada a la Dirección General de la clínica San Rafael y actualmente es la pieza más valiosa del museo, que está ubicado junto al Archivo Hospitalario Colombiano (AHC) en la clínica ${ }^{13}$. La estatua es de bulto, de $1,60 \mathrm{~m}$, del siglo XVII y policromada a manera de suntuoso brocado adornado con profusión de flores y arabescos. Como es característico en la imaginería del santo hospitalario, coronado de espinas, con una granada en su mano derecha y una cruz, en este caso evidentemente no la original, en la izquierda. Antes de su restauración, la parte media del hábito había sido retocada en dorado, dándole un aspecto particular. La estatua poseía una diadema y ajuar para vestir en su fiesta, que se celebraba con toda solemnidad principalmente en el siglo XVIII (Figura 3).

${ }^{12}$ RUBIO, Ozías y BRICEÑO, Manuel: Tunja, desde su fundación hasta la época presente. Bogotá, 1909, p. 148.

13 "Cédula de la estatua San Juan de Dios del siglo XVII que fue del hospital de la Purísima Concepción de Tunja". AHC (Archivo Hospitalario Colombiano), Provincia Colombiana Señora del Buen Consejo (2005). 
En la visita al convento-hospital de la Concepción de Tunja de enero de $1705^{14}$, se relacionan el mismo reducido grupo de imágenes, pero consignándose la presencia de un altar con una efigie de bulto adicional del beato Juan Pecador ${ }^{15}$, actualmente en paradero desconocido. Durante el resto del siglo XVII y buena parte del XVIII, el hospital de la Purísima Concepción de la ciudad siguió prestando atención a los pobres enfermos en su pequeño local.

\section{EL CENIT DE LA ORDEN HOSPITALARIA}

En 1738, fue nombrado general de la orden el hermano Alonso Pardo y Ortega de Jesús, apodado "El Magno", por sus grandes logros en el fortalecimiento económico y lustre de la religión en la metrópoli. En 1757, con ocasión de la inauguración de la basílica de San Juan de Dios en Granada, fue investido general perpetuo de la Orden Hospitalaria hasta su muerte en 1771. Según Alberro, los hospitales de la orden en Andalucía y Castilla, así como la edificación de la basílica del fundador en Granada y la remodelación del hospital anexo, recibieron cuantiosas limosnas del general Pardo y Ortega, "buena parte de las cuales provenían de las casas indianas. Esta política fue muy costosa y las provincias de Indias [...] fueron sometidas a una presión constante por parte del general para que aportaran caudales tan importantes"16.

El 13 de febrero de 1756, en el palacio del Buen Retiro de Madrid, Carlos III firma una real cédula dirigida a las justicias indianas, con el fin de que hagan observar puntualmente la ley $5^{\mathrm{a}}$, título $4^{\circ}$, libro $1^{\circ}$ de la Recopilación de Indias, "que trata del modo de visitar y tomar las cuentas de los Hospitales encargados a la

14 "Cuentas del convento hospital de la Pura y Limpia Concepción de la ciudad de Tunja de la orden de San Juan de Dios, hecha por fray Bartolomé Calvo, comisario general, el 26 de enero de 1705". AHC, Provincia de San Bernardo y Tierra Firme, sección Comunidades y Obras apostólicas-casas, 1705, caja 6.

15 Juan Grande (1546-1600) nació en Carmona, Andalucía, en 1546. A los 15 años perdió a su padre y se fue a vivir a Sevilla. Al cumplir 22 distribuyó sus bienes entre los pobres y se retiró a una ermita. Se presentaba no como Juan Grande, sino como el Grande Pecador. Un día encontró a dos vagabundos enfermos y los condujo a su choza, los atendió y salió a pedir limosna para alimentarlos. Vio así su vocación. Se trasladó a Jerez donde obtuvo autorización para atender a los presos. Tres años vivió en condiciones terribles de las limosnas que recogía puerta a puerta. Cuando una acaudalada pareja de la ciudad fundó un hospital, lo dejó en manos de Juan Pecador. Con el fin de que su obra no muriera con él, afilió su hospital a la congregación de Juan de Dios. Murió a los 54 años a causa de la peste en Jerez. Fue beatificado en 1853 y canonizado en 1996. REPETTO, José: El hermano Juan Pecador: Biografía critica del beato Juan Grande O. H., fundador del Hospital Jerezano de la Candelaria (1546-1600). Jerez, 1984.

${ }_{16}$ ALBERRO, Solange: Apuntes para la historia..., op. cit., pp. 201-202. 
orden de San Juan de Dios"17. El rey pide a todos los superiores de las órdenes religiosas que tuvieran conventos en América enviar a cada provincia un religioso visitador para hacer en sus conventos la reforma, "cortando con mano dura las corruptelas que se hubieran introducido"18. Debían nombrar un visitador principal, un secretario y un visitador segundo para cada provincia con el beneplácito del rey y el Consejo Superior de Indias. Fue nombrado para la provincia de San Bernardo, primer visitador, fray Nicolás de la Concepción Delgado ${ }^{19}$.

Entre 1774 y 1778, se realiza la visita reforma que cubre los catorce conventos-hospitales administrados por la Orden Hospitalaria en la provincia de San Bernardo, Tierra Firme y Nuevo Reino de Granada, a cargo del reformador principal de la orden. En 1776 se hace la visita reforma del convento-hospital de la Purísima Concepción de Tunja. El 27 de septiembre de 1776, Delgado, el visitador reformador, inicia la visita al pequeño convento hospital tunjano. Como en todas las visitas, lo primero, según la costumbre, es convocar a son de campana a la comunidad en la celda prioral, que sirve de sala capitular; el visitador reformador mandó al prior Roque Murillo entregar los libros de recibos, gastos y los de la administración y gobierno del hospital. En la capilla mayor de la iglesia encontró un relicario de plata con el santo óleo; en los altares, comenzando por el mayor, halló un tabernáculo grande dorado con una custodia de plata sobredorada y seis nichos repartidos en el retablo en los que estaban imágenes de "Cristo crucificado, Nuestra Señora de la Concepción, Nuestro padre san Juan de Dios, señor San Rafael, Santo Domingo y San Carlos Borromeo"20.

Existen en la primera iglesia 29 lienzos grandes con marcos dorados, 27 ingresados durante la administración de los hospitalarios, un altar del Espíritu Santo de talla, un relicario pequeño para llevar el viático a los enfermos y un altar de la Virgen de la Concepción con el lienzo primitivo del siglo XVI. En el cuerpo de la iglesia existen otros cinco altares: de San José, con cuadros de San José y Santa Ana; de San Cayetano, con lienzo del santo que atendió a los enfermos; de San Francisco Javier, retablo nuevo con un lienzo del santo; de Santa Bárbara, con una imagen de vestir; de San Juan de Dios, con un lienzo sobre el tránsito del santo; otro pequeñito con la Virgen del Rosario; y "otro con la ymagen de los dolores con sus albortantes [arbotantes] de talla dorada con su gotera y peaña dado todo de negro y flores de oro y de colores" ${ }^{\prime 2}$. En el coro alto, 10 pinturas más

${ }_{17}$ AGI, Indiferente 448, leg. 49, (1756), ff. 61v-62v.

18 Ibidem.

19 GÓMEZ, Juan Ciudad: Historia de la Orden Hospitalaria de San Juan de Dios. Palencia, 1963, p. 200.

20 "Testimonio de la visita reforma del hospital de la ciudad de Tunja por fray Nicolás de la Concepción y Delgado, visitador reformador. 27 de septiembre de 1776". AGN (Archivo General de la Nación), sección Hospitales, tomo IV (1776), ff. 902r-1003v.

${ }^{21}$ Ibidem. 
con marco dorado, un facistol y cuatro escaños. En la sacristía encuentra un San Antonio de bulto y 37 cuadros viejos. Hay tres campanas con sus cuerdas y el cementerio con su cerca y puerta, por donde cruza la acequia de agua rumbo a la plaza mayor. En la enfermería de hombres, se encontró un altar con un lienzo del Señor Crucificado con la imagen de Nuestra Señora, un sagrario dorado que custodia la ampolleta del santo óleo de plata y la efigie de bulto de Juan Pecador ${ }^{22}$.

De la primera descripción de 1642 a la de la reforma de la orden de 1776, la iglesia del convento hospital había adquirido una importante colección de imágenes de bulto y cuadros de santos a los que se les atribuían propiedades taumatúrgicas. Las imágenes más importantes de la iglesia hospitalaria de Tunja seguían siendo la Inmaculada Concepción, San Juan de Dios y San Rafael, el arcángel de la salud ${ }^{23}$.

En la visita los hospitalarios constataron el deterioro de la construcción del primer local del hospital y de su iglesia, tras más de dos siglos de uso y ampliaciones. En el marco del reformismo borbónico, la expulsión de los jesuitas en estos mismos años hace posible el traslado a un amplio convento e iglesia en el centro de la ciudad. Los hospitalarios experimentarán en su próxima sede su época de mayor esplendor en Tunja, aumentando la capacidad del hospital y el número de imágenes de la iglesia, combinadas ahora con las de los jesuitas. Los hospitalarios están en el cenit de su orden en la monarquía hispánica y en Tunja pasarán a la esquina de la plaza mayor en plena parroquia de Santiago.

\section{EL CONVENTO-HOSPITAL DE TUNJA EN SAN IGNACIO (1788-1822)}

Las reformas borbónicas producen cambios importantes en el hospital tunjano; no solo se aumentan los libros del hospital y el control de los ingresos y gastos, también se introducen a los soldados en el hospital de caridad, al que se le enquista un hospital militar, que lo termina consumiendo. Las reformas posibilitan al hospital abandonar su primera sede muy deteriorada y recibir el colegio con la iglesia, los paramentos y objetos sagrados de los expulsados jesuitas y, además, "aplicándose al hospital un principal de la cofradía de la Virgen que tenía dicha iglesia", la de la Virgen de los Dolores ${ }^{24}$. En el brazo del crucero del costado sur de la iglesia se encontraba el camarín de Nuestra Señora de los Dolores construido en el siglo XVII. En un documento de 1775 de la Junta de Temporalidades se refiere la iglesia como "muy adornada de primorosos altares entre los cuales

\section{${ }^{22}$ Ibid.}

${ }^{23}$ Rafael proviene del hebreo, significa "Dios sana" o "medicina de Dios". La palabra hebrea equivalente a médico es rofe, conectado con la misma raíz. En árabe se llama Israfil.

${ }^{24}$ AGUDELO, Benjamín: Los hijos..., op. cit., p. 850. 
sobresale el de Nuestra Señora de los Dolores, que tiene un vistoso camarín. Y esta imagen tiene para su culto mil pesos de fundación" 25 .

En 1777, la Junta Superior de Aplicaciones, tras reunirse en Santafé el 4 de marzo en presencia del virrey, teniendo en cuenta "la utilidad pública de que allí se trasladase el hospital por lo reducido en incómodo del actual”26, dándole plazo de seis meses, autorizó el paso del convento de San Juan de Dios y el hospital de la Limpia Concepción de su sede original al expropiado claustro e iglesia de San Ignacio. El cura de la iglesia mayor de Santiago solicitó el traslado del hospital de pobres enfermos "en vista que el que hay es muy reducido, húmedo y de estructura débil y deleznable, mayormente bañado en aguas que corren por la ciudad"27, con el apoyo del cabildo de Tunja, "por el notorio y útil beneficio que a la causa pública se siguió y ha seguido"28. El cabildo argumentó que el gasto continuo en reparaciones al antiguo hospital, que se hallaba en daño inminente, se podría remediar con el traslado y ese dinero aplicarse en beneficio de los pobres enfermos ${ }^{29}$.

El 2 de agosto de 1777, los hospitalarios de Tunja, con el padre prior Roque Murillo a la cabeza, reciben el céntrico inmueble al que se trasladan el 6 de mayo de 1778 y se disponen a acomodarlo a su nueva función hospitalaria ${ }^{30}$. En el documento de entrega de la iglesia de San Ignacio por parte de la Junta de Temporalidades, se consigna el contenido de la próxima iglesia del hospital de Tunja: "El tabernáculo del altar mayor todo dorado, con doce efigies de bulto; el sagrario todo en dorado y en la testera un espejo grande y en las puertas y cantoneras también espejos, nueve altares con sus respectivos tabernáculos dorados; los de

${ }^{25}$ GONZÁLEZ, Felipe: "Los edificios del colegio-noviciado de la Compañía de Jesús en Tunja, 1611-1767”, en Educadores, ascetas y empresarios. Los Jesuitas en la Tunja Colonial (1611-1767). T. II. Bogotá, 2010, p. 308. El espacio del antiguo camarín es usado hoy como bautisterio y la iglesia ha perdido gran parte de sus retablos e imágenes. En la historia de los hospitalarios, el camarín aparece en la segunda sede, antes jesuítica, y continúa adaptado para la Virgen de los Dolores en un camarín que existió en la iglesia de San Agustín, tercera sede del hospital. Para Fajardo de Rueda, "el camarín de la Virgen María en el arte barroco hispano tuvo un extraordinario significado simbólico. Era un espacio autónomo, relacionado con la vida supra sacralizada de la Virgen María”. FAJARDO, Marta: "El retablo de nuestra Señora del Rosario del templo de Santo Domingo de Tunja", en Religiosidad e imagen. Bogotá, 2015, p. 99.

26 AGUDELO, Benjamín: Los hijos..., op. cit., p. 851.

27 DEL REY, José: Educadores, ascetas y empresarios. Los Jesuitas en la Tunja Colonial (1611-1767). T. II. Bogotá, 2010, p. 338.

28 AGUDELO, Benjamín: Los hijos..., op. cit., pp. 851-852.

${ }^{29}$ Ibidem.

${ }^{30}$ Ibid. 
los ocho, y el uno sin dorar y en ellos sus correspondientes efigies, unas de bulto otras de retablo" 31 .

Los altares que pasan a manos de los hospitalarios fueron los siguientes: "Uno de San Ignacio de retablo; otro que sigue de la Virgen de los Dolores en su Camarín; otro de la Virgen de Nuestra Señora de Gracia con seis cuadros, entre estos dos grandes dorados y uno pequeño; otro del Niño Dios, con adornos y vestuarios y un sitial pequeño dorado; otro de San Francisco Javier con su retablo; otro de San Estanislao; otro de la Soledad; otro de San Juan Nepomuceno, desbaratado que está en armazón; otro de la Virgen de Loreto, también desarmado. Y todos los dichos altares con sus correspondientes velos, colaterales y frontales dorados. En dicha iglesia doce cuadros dorados y 20 en bastidor" ${ }^{32}$ (Figura 4).

El 9 de marzo de 1781 llega fray Miguel de Isla ${ }^{33}$, visitador de los hospitales del reino, al convento-hospital de Tunja. El 10 de marzo visita la iglesia, para lo que se cantó misa de rigor con toda la solemnidad. El sagrario se reconoció seguro y muy decente; la custodia de plata sobredorada y el santo óleo se halló suficiente. Visita el camarín de Nuestra Señora de Dolores, que tiene un altar con seis efigies de bulto de medio cuerpo y, el pecho de cada una, hueco, con cierre posterior y en la parte anterior un óvalo de vidrio con fragmentos de huesos pequeños y pedacitos menudos que parecen reliquias. En dos cajones del retablo, cuatro figuras de madera del brazo con un cóncavo cubierto con vidrio con fragmentos de huesos, con nombres de santos y dos baúles forrados en terciopelo y dentro envuelto en papeles y seda, huesos enteros, cúbito, radio y húmero, identifica Miguel de Isla, con letreros con nombres de santos mártires. Hallaron varios huesos cuyos letreros decían ser cuerpos enteros de mártires. Los documentos de

${ }^{31}$ DEL REY, José: Educadores..., op. cit., p. 320.

32 Ibidem.

${ }^{33}$ Miguel de Isla (ca. 1761-1807) nació en Santafé. Bachiller y maestro de Filosofía en la universidad de los jesuitas. En 1761 ingresó en la Orden Hospitalaria de San Juan de Dios y aprendió la medicina en el hospital de Santafé. En 1770 el general de la orden le da licencia para ejercer la profesión médica y es enviado a los hospitales de Pamplona, Panamá y Cali. En 1793, el virrey Solís le ordena retornar a Santafé para encargarse de la dirección del hospital de San Juan de Dios y atender a la tropa. Superior interino y visitador de la Orden Hospitalaria, en 1778 obtuvo dispensa pontificia para retirarse de la orden. Como religioso de la arquidiócesis de Santafé se dedicó a trabajar en el Jardín Botánico con José Celestino Mutis, quien fue su maestro. En 1801 el virrey Mendinueta ordena la creación de la cátedra de Medicina en el colegio de El Rosario y de Isla fue escogido para regentarla. Una real cédula lo nombró catedrático de Medicina sin necesidad de tener graduación previa. En 1803 solicitó se le concediera el título de médico que obtuvo en 1806. Es sepultado en la iglesia del hospital San Juan de Dios de Santafé en 1807, a cuyos pobres enfermos les dejó sus bienes para que pudieran tener "desayuno de chocolate y bizcochos”. GÓMEZ, Jaime: Diccionario Biográfico Médico Hispanoamericano. Caracas, 2007, pp. 290-291. 
autenticidad de las reliquias no se hallaron. De Isla pide que se soliciten a Santafé las certificaciones y, si se conseguían, se expusieran las reliquias a la pública veneración ${ }^{34}$.

El visitador consigna el "exceso que se notaba en algunas partidas del gasto ordinario" en la iglesia. El prior aduce que en el nuevo hospital es "mayor el número de religiosos y enfermos que ha tenido en el tiempo de su gobierno" y que el gasto de la iglesia, se debía a haber celebrado las fiestas con mayor suntuosidad. Agrega el prior que no había procedido de malicia y que para sanear las rentas consignaba 100 pesos, "para el pagamento de una efigie de señor San Rafael, que se condujo desde Quito y se halla en esta iglesia" 35 , estatua quiteña de bulto del arcángel San Rafael, hoy en paradero desconocido.

\section{EL HOSPITAL EN SAN AGUSTÍN Y EL PATRONATO REPUBLICANO (1822-1835)}

Con el fin de las guerras de Independencia (1815-1824) se inicia la organización del nuevo Estado. La República toma importantes medidas para el control y creación de instituciones educativas y de salud pública ${ }^{36}$. El gobierno de Colombia asumió el antiguo Patronato Real, quedando bajo la tutela directa del gobierno republicano las comunidades religiosas, el clero secular, los hospitales, colegios y universidades ${ }^{37}$.

La República realizó múltiples cambios en la administración y funcionamiento de las instituciones que pertenecieron al Patronato Real como los hospitales de la orden de San Juan de Dios. Así, los de Tunja pasaron del exconvento de la Compañía al pequeño y alejado convento de Santiago de los agustinos calzados, suprimido por el gobierno en los años veinte del siglo XIX y ubicado en la plaza de abajo, lugar donde se harían cargo de la iglesia de San Agustín con todas sus alhajas, altares e imágenes, de forma similar a como sucedió con la de los jesuitas al finalizar el XVIII. A esta última iglesia corresponde la visita realizada el 5 de agosto de 1831, que describe la nueva iglesia hospitalaria con todos sus altares.

34 "Visita local y real del convento hospital de Tunja, actuada en 10 de marzo de 1781”. AHC, Provincia de San Bernardo y Tierra Firme, sección Comunidades y Obras Apostólicas-casas, 1781, caja 9.

35 Ibidem.

36 "Fundación para la Conmemoración del Bicentenario del Natalicio y el Sesquicentenario de la muerte del General Francisco de Paula Santander", en Actas del Congreso de Cúcuta 1821. T. II. Bogotá, 1990, pp. 121-122.

${ }^{37}$ Mediante el Decreto de 5 de julio de 1820, el gobierno de la nueva República anuncia que hará uso del derecho al Patronato. YOUNG, John Lane: La Reforma Universitaria en Nueva Granada. Bogotá, 1994, p. 37. 
Fray Tomas Cárdenas, visitador de la orden, inició la ceremonia en la iglesia, donde encontró un sagrario con velas encendidas y un copón de plata sobredorado y una custodia. De las reliquias no quedaba ninguna: "unas habían sido trasladadas a Bogotá y otras se habían perdido en tiempo de los síndicos" 38 . Se da cuenta de los altares y estatuas y del estado general de la iglesia. En la sacristía "advirtió que de plata no había más que los dos cálices, un par de vinajeras, el copón y la ampolleta de los santos oleos" ${ }^{39}$, situación que contrasta con las descripciones de las iglesias anteriores de los hospitalarios. En la celda del prior se encontró un baúl con un vistoso vestido para el arcángel San Rafael: "un par de alas nuevecitas de plata con sus tornillos y tuercas de plata maciza, el pescado, calabazos y báculo" 40 .

Al año siguiente, el mismo visitador Tomás Cárdenas, quien figura como administrador del convento hospital de Tunja, realizó una "carta cuenta e inventario" de la iglesia, con el fin de remitirla al provincial hospitalario y a su definitorio, a celebrarse el 3 de mayo de 1832. Esta es la descripción más completa de la iglesia del convento hospital en su sede de San Agustín hasta ahora encontrada y sirve para rastrear el paradero de estatuas, cuadros y altares ${ }^{41}$. Para ese año, la situación de la orden en Colombia era muy precaria, pues estaban a punto de abandonar sus hospitales en toda la República.

El convento tiene "su buen cañón de iglesia con diez altares, dos pilas bautismales de piedra y, a la derecha, una capilla con seis altares". Un altar mayor dorado con tres cuerpos, en el primero de los cuales está el sagrario circular y a la derecha la estatua de San Juan de Dios con un Cristo en la mano derecha y una

38 "Carta Cuenta e inventario del Convento Hospital de Tunja. 1831". AHC, Provincia de San Bernardo y Tierra Firme, sección Comunidades y Obras Apostólicas-casas, 1831, caja 6. En la Guía de Tunja de 1939, del cuarto centenario de su fundación, se menciona que en la ermita del siglo XVII de las Nieves, cercana a San Agustín, al norte de la ciudad, "se conservan cuidadosamente reliquias de San Fabián, San Cosme, San Damián, San Blas y Santa Lucia". SALAMANCA AGUILERA, Rafael: Guía Histórica Ilustrada de Tunja. Tunja, 1939, p. 62. La única referencia en textos del siglo XX de reliquias en las iglesias tunjanas de santos mártires recurridos en caso de enfermedad como Cosme y Damián, gemelos patrones de la cirugía; Santa Lucía virgen y mártir, patrona de los pobres, los ciegos, los niños enfermos y las ciudades; el médico, obispo y mártir de Asia Menor San Blas, patrón de los enfermos de garganta; y el décimo pontífice y mártir San Fabián, quien instituyó el santo crisma y su consagración el Jueves Santo. La ermita de las Nieves desapareció en los años 70 del siglo XX para dar paso a una iglesia en ladrillo. Las reliquias se encuentran en paradero desconocido.

${ }^{39}$ AHC, $1831 \ldots$, op. cit.

40 Ibidem.

41 "Carta Cuenta e inventario del Convento Hospital de Tunja. 1832". AHC, Provincia de San Bernardo y Tierra Firme, sección Comunidades y Obras Apostólicas-casas, 1832, caja 6. 
granada en la izquierda, corona de espinas y diadema, "camisa y calzoncillos de lino" y su hábito de tafetán negro y a la izquierda la estatua del arcángel San Rafael con sus alas plateadas como su coronita y capa, imágenes que han recorrido hasta aquí un largo camino". En el segundo cuerpo del altar mayor están las estatuas de San Carlos Borromeo y la de Santo Domingo, que vienen del primer hospital y un Niño Jesús. En el tercer cuerpo, está un San Salvador y dos efigies de religiosos agustinos ${ }^{42}$.

Hacia la puerta de la iglesia en la nave derecha está la entrada a la sacristía y un altar dorado de la "Niña de la Luz" con su velo y un cuadro San Ignacio en el nicho superior. Otro altar dorado está dedicado a Nuestra Señora de Loreto, viéndose en un costado dos santos de medio relieve y la Virgen toda vestida de brocado colorado, así como el Niño. En la misma capilla se encuentra un altar claramente agustino, que sin embargo tiene como protagonista al llamado "taumaturgo del siglo XVI" San Salvador de Horta ${ }^{43}$. Por sus atributos y descripción, se ha identificado su paradero actual en un altar lateral de la iglesia de El Topo del siglo XVIII, antiguo hogar de los agustinos descalzos y hoy de las concepcionistas. En San Agustín el santo catalán tuvo como acompañantes imágenes de caballete con marco dorado de Santa Bárbara y San José, y en la parte superior los cuadros de San Agustín con Santa Rita, San Nicolás al centro y, al otro lado, a San Cristóbal y la Virgen del Rosario.

La capilla, hoy vacía, tenía un altar tallado y dorado con un cuadro que representaba el tránsito de San Juan de Dios, a la izquierda un cuadro de la Santísima Trinidad y a la derecha uno de la pasión de Jesús Nazareno; encima otro cuadro de la Virgen del Rosario y un remate de San Antonio Abad. Otro de los altares que existió en este estrecho lugar fue uno dedicado al jesuita San Francisco de Borja, rodeado por dos cuadros de la Virgen de la Soledad y la de Guadalupe, todo rematado arriba por un cuadro de Santa Teresa de Jesús.

En la capilla izquierda de esta iglesia de cruz latina se halla el altar del patriarca San José de bulto, "de cuerpo entero con su niño Dios de un tamaño regular con sus tres potencias de cobre: el santo con su vestido y capa de brocado,

42 Ibidem.

${ }_{43}$ Salvador Pladevall y Bien (1520-1567) fue un franciscano que ejerció la caridad en Aragón. Nació en el hospital de la villa en Santa Coloma donde sus padres servían a los pobres enfermos. Huérfano en 1534, se traslada a la ciudad condal, donde ejerce distintos oficios, entre ellos el de zapatero. En 1541 ingresó al convento franciscano de Barcelona, donde profesó en 1542. Estuvo en distintos conventos, uno de ellos el del pequeño poblado de Horta, donde empezó su fama de taumaturgo, dedicándose a las tareas de la cocina, la huerta, la portería y a pedir limosna, pero la cantidad de gente que lo buscaba le ocasionaba problemas a los conventos donde iba y con la Inquisición, por lo que es enviado a Cerdeña donde fallece. Es beatificado en 1606 y canonizado ya en el siglo XX, en 1938. Ver DOMENEC, Fray Antonio Vicente: Historia general de los santos y varones ilustres en santidad del Principado de Cataluña. Gerona, 1630, pp. 329-335. 
su cabellera y azucena de flor de mano"44, imagen que, según hemos podido identificar, se encuentra hoy en la iglesia de El Topo. A los costados, dos cuadros de marco dorado con San Luis Gonzaga y de la Compañía de Jesús el otro ${ }^{45}$, y remata una Virgen de Chiquinquirá con su marco dorado y al lado otro cuadro de San Agustín y uno de San Nicolás. Al pie de este altar estaba un sagrario dorado con un San Ignacio con marco de carey y un Espíritu Santo de yeso. A la izquierda una puerta de acceso al camarín de Nuestra señora de los Dolores. Completa la estrecha capilla un altar pequeño con un cuadro de Santo Domingo rematado por un cuadrito del Señor de la Columna ${ }^{46}$, imagen que fue un tema clásico de la pintura en la ciudad desde el siglo XVI y del que se pueden encontrar hoy copias en varias iglesias de la ciudad.

El altar de San Juan Nepomuceno es tallado y dorado y tiene a sus lados dos cuadros, uno del Señor de la Columna con San Pedro, del que ya se ha hablado, y otro del Niño Jesús con la Verónica. En el remate tiene un cuadro de Nuestra señora de los Dolores; a los lados dos cuadros, uno de San Cayetano y otro del Niño Jesús como buen pastor. Al pie de este altar está un sagrario con un San Luis Gonzaga con marco negro y vidriera y encima una cruz ${ }^{47}$.

Un altar del calvario con un Santo Cristo de cuerpo entero y su cruz de madera pintada de verde con un San Juan y Magdalena con vestidos de lienzo; a la derecha e izquierda dos cuadros de marco, uno de San Nicolás de Bari y otro de Nuestra señora del Tránsito. Encima del Cristo un cuadro de Santa Teresa de Jesús y, a derecha e izquierda, dos cuadros grandes de la Inmaculada y Nuestra Señora de Belén. Finaliza esta capilla un altar con un cuadro de retablo grande del Nazareno ${ }^{48}$.

La capilla de Nuestra Señora de los Dolores tiene siete altares, dos sin imágenes con sus columnas doradas. A la derecha un cuadro de la Santísima Trinidad y otro de las Ánimas, que tiene en sus cuatro ángulos la muerte, el infierno, la gloria y la Santísima Trinidad, y en el centro del retablo el Redentor. A la izquierda hay una pintura de Nuestra Señora de la Antigua ${ }^{49}$, en sus costados una

${ }^{44}$ Este bello San José de bulto se ha logrado identificar por su descripción y se encuentra hoy en el remate del altar mayor de la iglesia de El Topo. El altar clásico de la escuela de retablos de Tunja del siglo XVII es conocido como el "Trono de las Misericordias". La imagen central que ostenta hoy el altar es el del venerado cuadro de la Virgen del Milagro, Inmaculada renovada en el convento concepcionista en el siglo XVII, patrona de la ciudad.

${ }^{45}$ En la iglesia de El Topo, en el muro norte, se encuentra actualmente un pequeño cuadro de San Luis Gonzaga con su marco dorado, aunque ahora a los pies de un retablo de la Virgen del Rosario con Santa Catalina de Siena.

46 AHC, $1832 \ldots$, op. cit.

47 Ibidem.

48 Ibid.

${ }^{49}$ Una de las primeras advocaciones de la Virgen, también de origen sevillano, es Nuestra señora de la Antigua. Se cuenta con cuadros en varias iglesias de la ciudad, siendo 
pintura de Santa Gertrudis y de Santa Rita de Casia y en su remate Dios Padre. Enseguida, un cuadro del tránsito de San Nicolás y arriba un Niño Jesús. Sigue un cuadro de la Ascensión. El camarín de esta iglesia, adaptado para uso de la imagen de la Virgen de los Dolores, traída de San Ignacio, de bulto con su peana dorada y cruz forrada en carey. En el cañón de la iglesia hay dos frontales dorado y rojo y un cuadro de San Ignacio de Loyola ${ }^{50}$.

En el otro cañón un cuadro grande de la Virgen del Rosario, otro del Señor Crucificado, una Inmaculada con un Niño y enseguida un cuadro sin marco de San Fernando rey de España. Luego un cuadro de relieve del Salvador del mundo, otro con su marco dorado de San Ignacio de Loyola, luego otro de San Francisco de Asís. En el altar mayor, cuatro cuadros de Santa Catalina de Siena, Santa María Magdalena, Nuestra Señora del Rosario y la Virgen de Belén ${ }^{51}$. En el coro un cuadro de marco dorado de San Nicolás de Bari ${ }^{52}$.

En total 16 altares, en una iglesia que recoge la historia del hospital tunjano y sus tres sedes, donde se mezclan las imágenes a las que rinden devoción los hospitalarios de San Juan de Dios sin, al parecer, existir mucho problema de coexistencia con los santos y mártires de los expulsados jesuitas y los santos de los agustinos, los antiguos inquilinos del hospital. Se ha realizado esta descripción, ya que de las tres sedes del convento hospital, la de San Agustín, por múltiples avatares de su historia, posterior a la marcha de los hospitalarios, es la que no conserva ningún bien artístico (Figura 5).

En el acta del día 14 de mayo de 1835, el Congreso de Nueva Granada comienza la segunda discusión del proyecto de supresión del convento-hospital de Bogotá, en el que los diputados discuten una modificación a la ley, por la cual se suprime igualmente el convento-hospital de la orden de San Juan de Dios de Tunja, concluyendo los debates con la Ley del 18 de mayo de 1835, que suprime en la República los conventos-hospitales de la orden de San Juan de Dios tras 199 años de administrar el hospital de Tunja ${ }^{53}$.

\section{EL TOPO, CONCEPCIONISTA, JESUITA, AGUSTINO Y HOSPITALARIO}

Por mucho tiempo las referencias a la orden de San Juan de Dios y a su convento-hospital de la Purísima Concepción en la historia colonial de la ciudad de Tunja se habían limitado a la portada del desaparecido primer hospital. Pequeños

la más valiosa la pintada por el romano Angelino Medoro, que fue robada a principios de este siglo de la iglesia de San Ignacio.

${ }^{50}$ AHC, $1832 \ldots$, op. cit.

51 Ibidem.

52 Ibid.

${ }^{53}$ DE POMBO, Lino: Recopilación de Leyes de la Nueva Granada. Bogotá, 1845. 
fragmentos sobre la ubicación del hospital es posible encontrar en los historiadores académicos y de la medicina ${ }^{54}$.

La exploración reciente del Archivo Hospitalario Colombiano, aparte de haber aportado información amplia por primera vez sobre el desarrollo del hospital colonial como institución, los inventarios de las visitas y luego en el siglo XVIII, las cartas cuentas e inventarios de la orden han permitido una descripción de las importantes obras de arte contenidas en las tres iglesias de los hospitalarios en la ciudad, correspondientes a la antigua iglesia del hospital hoy desaparecida, la de San Ignacio y la de San Agustín. Estas dos iglesias hoy no conservan la mayor parte de lo que tuvieron a principios del siglo XIX; la de San Ignacio por pasar a ser colegio republicano, luego sala de conciertos y hoy volver al servicio del culto católico.

La de San Agustín pasó con su convento anexo a ser hospital hasta la extinción de la orden en 1835 y continuó en manos caritativas hasta 1863, cuando esta institución se trasladó al convento de Santa Clara la Real, el primer convento femenino del país, de cuya iglesia, los hospitalarios ya en el siglo XX se llevaron la estatua de su patrón. El claustro de San Agustín tuvo los más destructivos usos al ser cuartel, polvorín y luego panóptico, hasta ser abandonado, dinamitado, quedando en la ruina en los años 60 del siglo XX. Hoy su iglesia es una biblioteca en proceso de restauración, de la cual, hasta la descripción consignada aquí, no se tenía ninguna información.

Estas imágenes hospitalarias terminaron en iglesias como la del hospital de Caridad en Santa Clara la Real y algunas otras, reliquias incluidas, en la ermita de Las Nieves al norte de la ciudad. En 1939 se relacionaba en la desaparecida iglesia de las Nieves un cuadro grande de San Juan Nepomuceno ${ }^{55}$ que puede corresponder al mencionado en el inventario de la iglesia de San Ignacio al ser entregada a los hospitalarios, que tendría altar propio en San Agustín, hoy en paradero desconocido.

Desde el siglo XIX algunas obras de arte religioso han sido trasladas a Bogotá; es el caso de la imagen de bulto de Juan Ciudad, ya citada, o del San Rafael de bulto quiteño de 1,30 m que se encontraba en la iglesia mayor de Santiago, hoy catedral, enviado junto con otras obras de arte de iglesias de la ciudad a la exposición con motivo del Congreso Eucarístico Internacional de 1968 con la presencia de Pablo VI, cuyo último registro fue en el catálogo de esa exposición que fue realizada en la Biblioteca Luis Ángel Arango de Bogotá ${ }^{56}$ (Figura 6).

${ }^{54}$ RUBIO, Ozías y BRICEÑO, Manuel: Tunja..., op. cit.; y MARTÍNEZ ZULAICA, Antonio: Fosas y Bronces. La medicina en la ciudad de Tunja, su evolución histórica. Bogotá, 1989.

${ }_{55}$ SALAMANCA AGUILERA, Rafael: Guía Histórica..., op. cit., p. 62.

56 ARBELÁEZ, Carlos y GIL, Francisco: Arte religioso en la Nueva Granada Exposición XXXIX Congreso Eucarístico Internacional. Bogotá, 1968. 
A través de textos, guías de arte y catálogos fue posible identificar una particular y colorida pintura al óleo sobre lienzo asociada al antiguo hospital de la $\mathrm{Pu}$ rísima Concepción, que demuestra la diáspora de sus altares y retablos. En esta imagen, actualmente en el convento franciscano de la Magdalena de Tunja, una Inmaculada se encuentra acompañada de San Cristóbal a la izquierda y San Juan de Dios a su derecha ${ }^{57}$, lo que recuerda, por su composición y cercanía urbana, al cuadro de Narváez, imagen taumatúrgica asociada a la historia del arte y de la salud de la Tunja colonial (Figura 7).

El caso de las imágenes, altares y cuadros de la iglesia de El Topo es, sin lugar a duda, el principal aporte para la historia del arte colonial neogranadino que pretende este trabajo. De los cuadros en los altares descritos en la entrega de la iglesia de los jesuitas a los hospitalarios, los de San Ignacio y San Francisco Javier pasan a la iglesia de San Agustín a principios del siglo XIX y luego de la extinción de la orden hospitalaria y el desmantelamiento de la iglesia del hospital, pasan a El Topo, en un retablo rehecho por el maestro del movimiento Bachué Luis Alberto Acuña y el presbítero y miembro de la Academia Boyacense de Historia Ernesto Reyes Sarmiento, en su afán por ennoblecer la sencilla iglesia recoleta en los años 50 del siglo $X^{58}$. El pequeño cuadro del jesuita San Luis Gonzaga, que se referencia en la iglesia del hospital en el convento de San Agustín, forma parte hoy del retablo ensamblado por Acuña, que tiene en la mitad una Virgen del Rosario con Santa Catalina de Siena, cuadros del siglo XVII atribuidos al taller santafereño de Baltasar Vargas de Figueroa.

En la misma iglesia, Santiago Sebastián en 1963 identifica un altar de San Cristóbal que aparece también en el inventario hospitalario, así como un cuadro de Jesús joven como buen pastor que también pasa a El Topo desde la iglesia hospitalaria en San Agustín ${ }^{59}$; valga decir que en El Topo existe un retablo gemelo a este. De la misma manera, el San José con el Niño de bulto ya mencionado en el altar mayor, llamado también "Trono de las Misericordias", y la estatua del santo catalán Salvador de Horta en un altar lateral de El Topo. Llama la atención el uso temprano por parte de los hospitalarios de tres santos, en ese momento beatos, Juan de Dios, Juan Pecador y Salvador de Horta, representantes de la caridad cristiana exaltada por Trento.

Respecto a los niños Jesús de bulto y de vestir que figuran en el inventario de los jesuitas, el rastreo es más difícil. Solo agregamos que actualmente las concepcionistas de El Topo, en el Belén que se arma para Noche Vieja exponen una imagen de vestir hasta el día de Reyes y que, en el altar mayor de la iglesia de las Nieves, que es el que pertenecía a la vieja iglesia, aparece otro Niño Jesús desnudo

57 DAZA, Gloria: Herencia Colonial IV-Tunja. Bogotá, 1974, pp. 113-116.

${ }_{58}$ REYES, Ernesto: Escritos selectos. Tunja, 1994, p. 226.

${ }^{59}$ SEBASTIÁN, Santiago: Álbum de arte colonial de Tunja. Tunja, 1963, pp. XLVIII, XLIX y L. 
sobre un pequeño sitial dorado. Igualmente, en la iglesia de El Topo existe actualmente un cuadro cortado que representa a la Virgen de Belén, seguramente, uno de los dos reportados en el inventario hospitalario hecho en San Agustín en el siglo XIX.

En conclusión, la iglesia que reúne la mayor cantidad de elementos que pertenecieron a las iglesias en manos de los hospitalarios en su paso por Tunja, es la pequeña recoleta de El Topo, que se convierte en un repositorio y en una evidencia del, hasta hace poco, desconocido papel como conservador del arte colonial de jesuitas y agustinos que tuvieron los hospitalarios (Figura 8).

Sobre la historia de las concepcionistas y su convento solo se ha publicado un artículo que data de 1939. Sus bienes, como los de los hospitalarios, trasegaron por la ciudad; unos se perdieron al exclaustrarlas de su primitivo convento en la segunda mitad del siglo XIX para pasar al abandonado convento de El Topo, al que llevaron lo que pudieron, dentro de lo que se destaca el venerado cuadro de la Inmaculada conocido como la Virgen del Milagro. La bellísima Bailarina del taller quiteño de Bernardo de Legarda, sin alas, policromada y estofada, formó parte de El Topo desde su construcción.

Sin duda, este es solo un primer paso para identificar estas obras y su procedencia, clasificarlas, datarlas y darles contexto. La valoración artístico-estética de estas imágenes y retablos y el estudio de sus posibles escuelas, periodos y autores, requerirá de un trabajo interdisciplinario más extenso, que rebasa el objeto de este artículo y que involucre no solo el estudio de documentos de archivo, sino la historia del arte y la historia urbana del siglo XIX y el siglo XX, este último donde se produjeron los mayores cambios en la diáspora del patrimonio artístico de las iglesias tunjanas. Este trabajo aporta a la historia del arte colonial nueva documentación, que se espera sirva para la valoración, estudio, restauración y conservación adecuada de estas obras que permanecían anónimas, como la propia historia de los hijos de San Juan de Dios en la pequeña ciudad del altiplano del Nuevo Reino de Granada.

Fecha de recepción: 18 de octubre de 2018

Fecha de aceptación: 1 de julio de 2019 


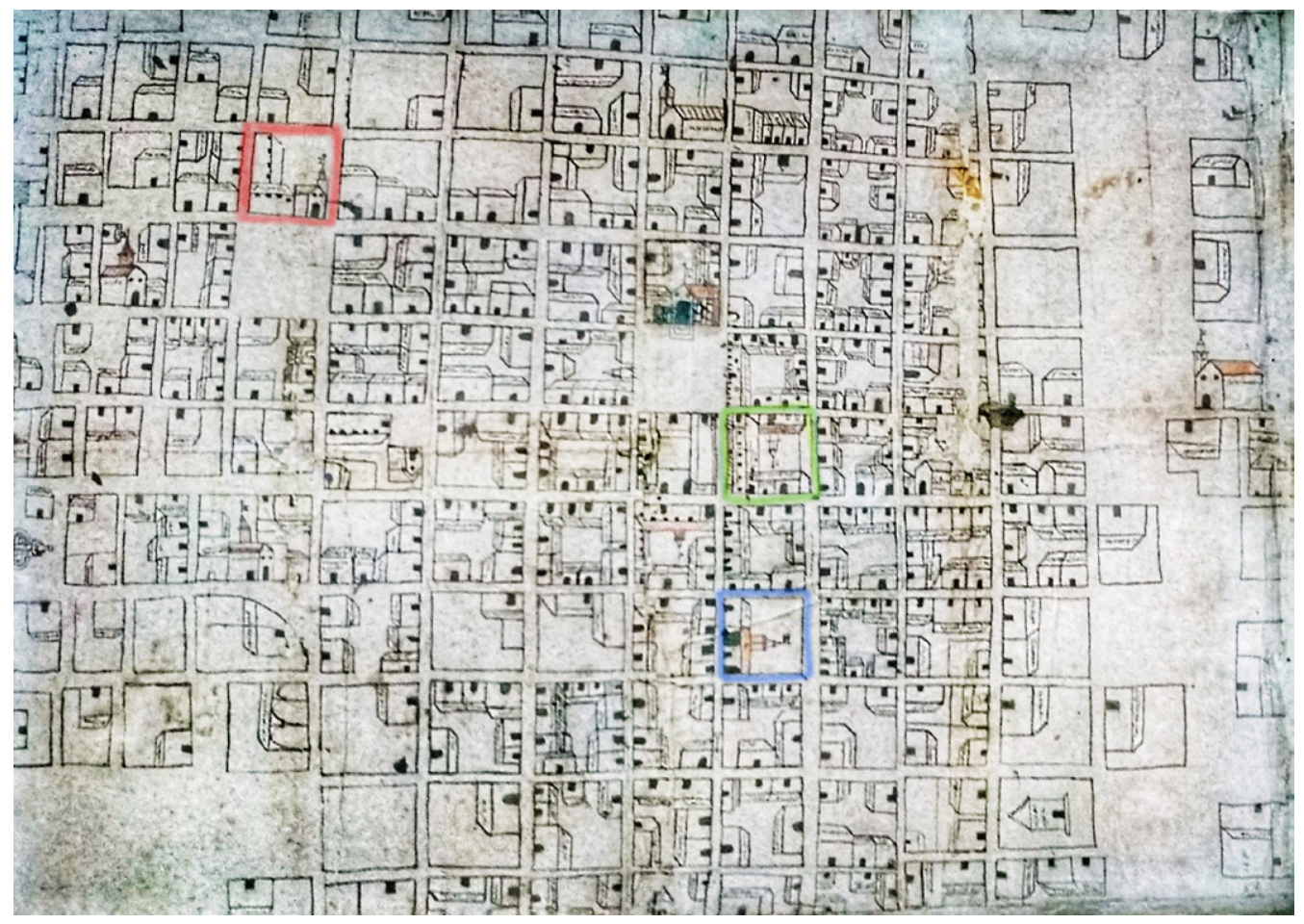

Figura 1. Plano de Tunja para la división de parroquias de 1623. Se señala en azul la primera sede del hospital de la Purísima Concepción con su iglesia, la cual ocupó desde su construcción en 1553 hasta su traslado al convento de la Compañía de Jesús en 1788, complejo que incluía la iglesia de San Ignacio, señalado en verde, en uno de los ángulos de la plaza mayor de la ciudad. En color rojo, el convento de los agustinos calzados y su iglesia de San Agustín en la llamada plaza de abajo, tercera sede del convento de San Juan de Dios y el hospital, trasladado por el gobierno de la República de Colombia en 1822 y en donde permaneció la Orden Hospitalaria hasta 1835. 


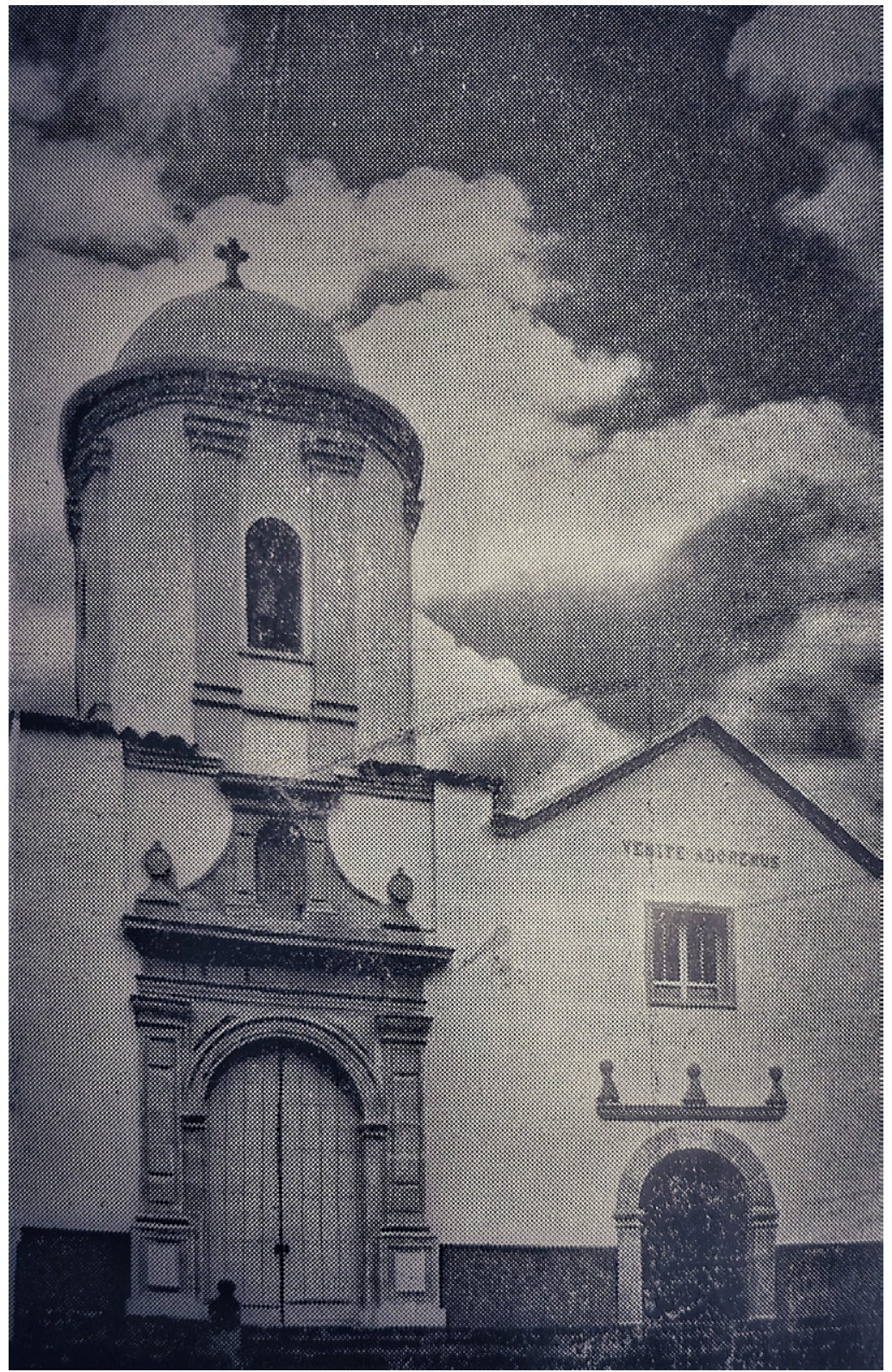

Figura 2. Portada de la iglesia del hospital de la Purísima Concepción de Tunja, trasplantada a la iglesia de El Topo, Tunja (Colombia). SALAMANCA AGUILERA, Rafael: Guía Histórica..., op. cit., p. 87. 
Figura 3. Anónimo, San Juan de Dios, siglo XVII, 1,60 m, MuseoArchivo Provincia Colombiana de Nuestra Señora del Buen Consejo (antigua clínica San Rafael), Bogotá (Colombia). Foto: Eduard Viancha, 2017.

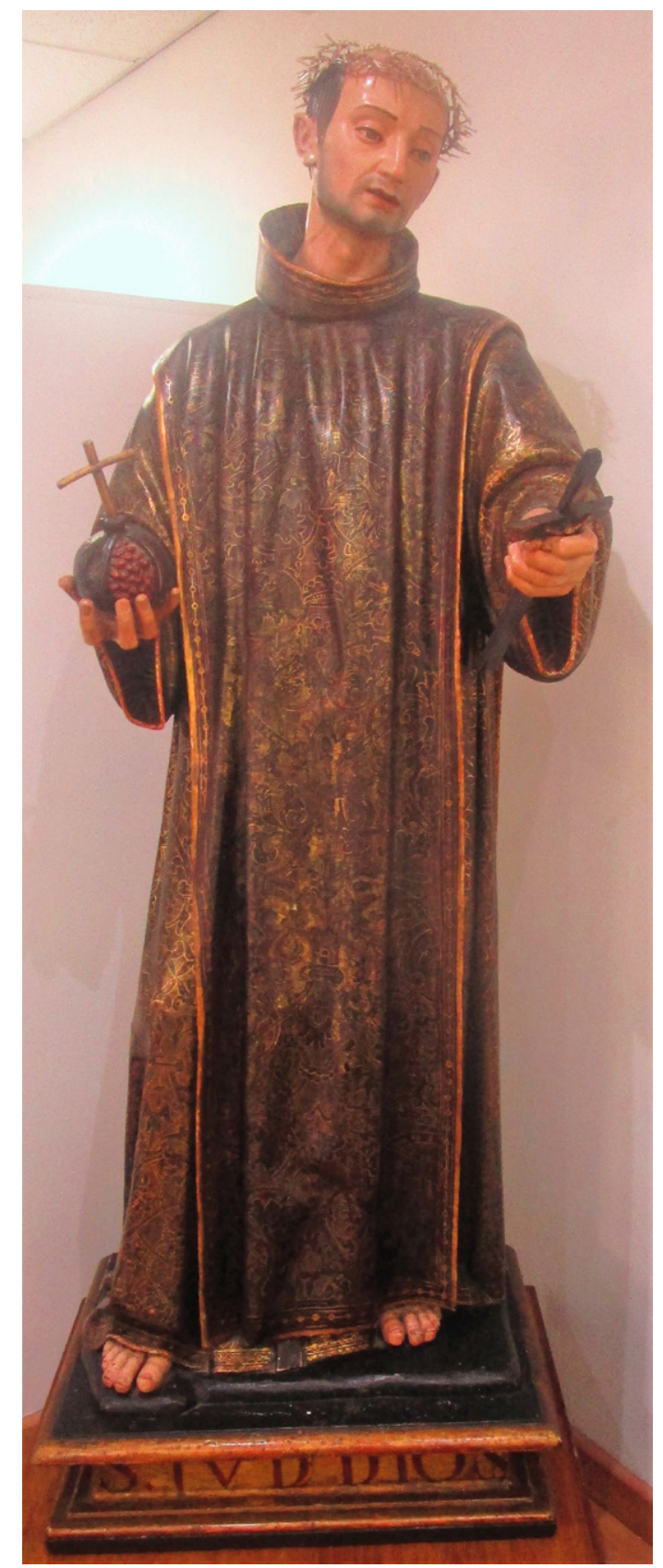

LABORATORIO DE ARTE 31 (2019), pp. 161-184, ISSN 1130-5762 e-ISSN 2253-8305 - DOI http://dx.doi.org/10.12795/LA.2019.i31.10 




Figura 4. Retablo mayor, iglesia de San Ignacio, Tunja (Colombia). IRIARTE, Alfredo: Tesoros de Tunja. Bogotá, 1990, p. 103. 




Figura 5. Aspecto actual como biblioteca del Banco de la República de la iglesia de San Agustín (Tunja, Colombia) desde el coro. Se observan los vestigios de su pintura mural y el crucero. A la izquierda el acceso desde el claustro del convento y a la derecha los dos arcos de la capilla con el camarín que los hospitalarios consagraron a Nuestra Señora de los Dolores. Foto: Luis Antonio Buitrago Bello, 2007.

Figura 6. Anónimo, San Rafael Arcángel, siglo XVIII, 1,30 m. Según el catálogo de 1968, pertenece a la catedral de Tunja (Colombia). ARBELÁEZ, Carlos y GIL, Francisco: Arte religioso en la Nueva Granada..., op. cit, lám. 24.

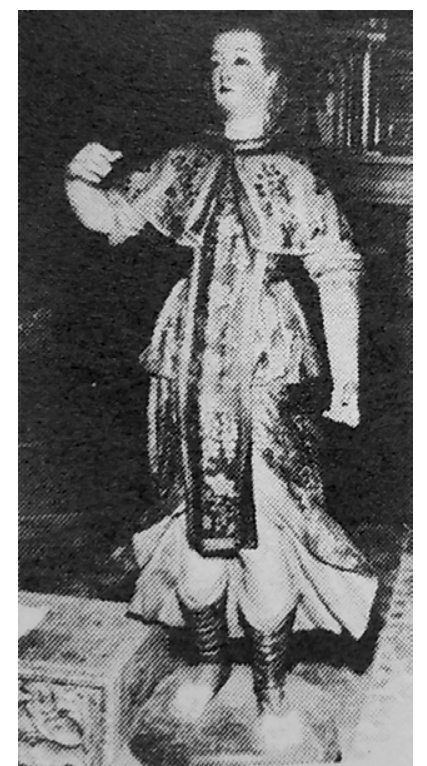




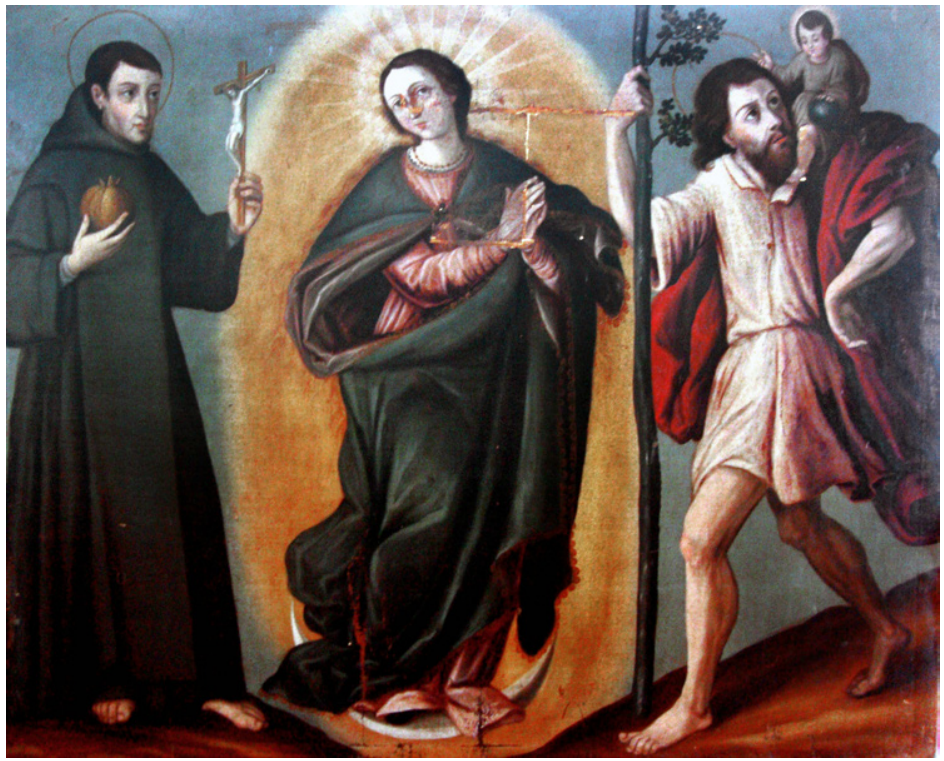

Figura 7. Anónimo, Inmaculada con San Juan de Dios y San Cristóbal, óleo sobre lienzo, convento de la Magdalena de los franciscanos, Tunja (Colombia). DAZA, Gloria: Herencia Colonial IV ..., op. cit., p. 113.

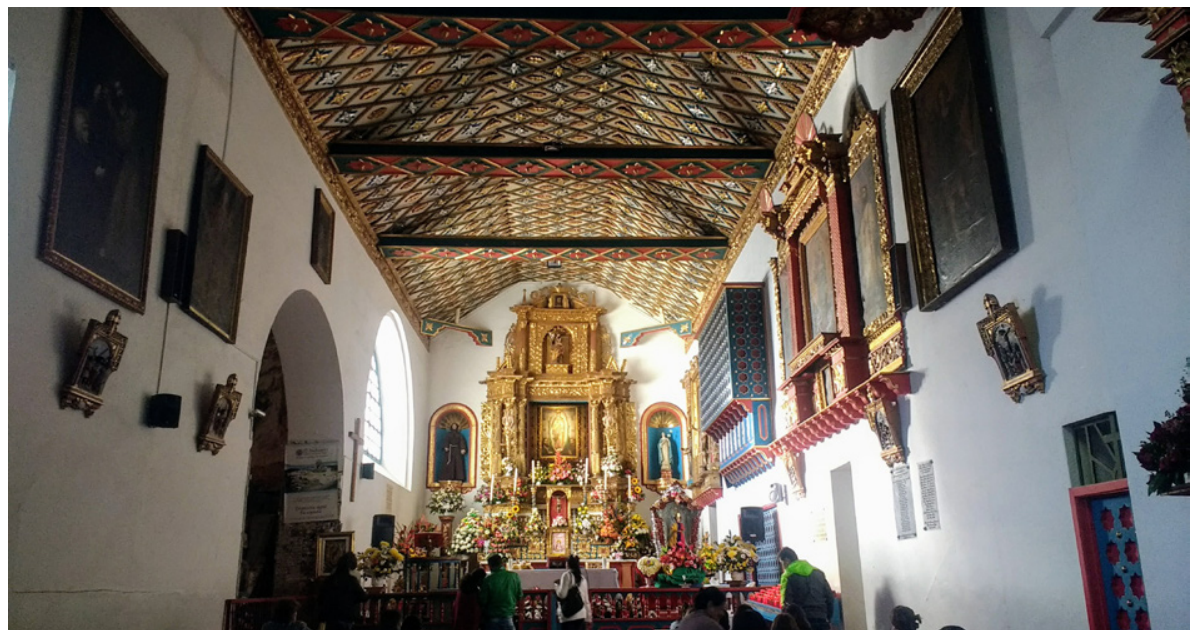

Figura 8. Vista actual de la iglesia de El Topo. Al fondo, el altar llamado el "Trono de las Misericordias" con el cuadro de Nuestra Señora del Milagro; sobre él un San José con el Niño Jesús, a la derecha los altares del cuadro de la Virgen del Carmen con las estatuas de bulto de San Salvador de Horta y San Expedito y los cuadros de la Virgen del Rosario con San Ignacio de Loyola y San Francisco Javier. Foto: Andrés Otálora, 2018. 